\title{
Unveiling Mechanochemistry: kinematic-kinetic approach for the prediction of mechanically induced reactions
}

Eva Gil-González, ${ }^{\mathrm{a}, \mathrm{b}^{*}}$ María del Rocío Rodríguez-Laguna, ${ }^{\mathrm{a}}$ Pedro E. Sánchez-Jiménez Antonio Perejón, ${ }^{\mathrm{a}, \mathrm{c}}$ Luis A. Pérez-Maqueda ${ }^{\mathrm{a}^{*}}$

anstituto de Ciencia de Materiales de Sevilla, Consejo Superior de Investigaciones Cientificas-Universidad de Sevilla. Calle Américo Vespucio 49, Sevilla 41092, Spain

${ }^{b}$ Departamento de Ingeniería Química, Universidad de Sevilla, Escuela Politécnica Superior, Calle Virgen de África, 7, Sevilla, 41011, Spain

${ }^{c}$ Departamento de Química Inorgánica, Facultad de Química, Universidad de Sevilla, Sevilla 41071, Spain

Corresponding authors: Eva Gil-González: eva.gil@icmse.csic.es, Luis A. Pérez-Maqueda: maqueda@cica.es.

\begin{abstract}
Mechanochemistry has attracted a lot of attention over the last few decades with a rapid growth in the number of publications due to its unique features. However, very little is known about how mechanical energy is converted into chemical energy. Most of the published works using mechanochemistry neglect the required attention to the experimental parameters and their effect over the resulting products, what makes extremely difficult to reproduce the results from lab to lab. Moreover, if it is taken into consideration the broad range of experimental conditions used in different studies, it is quite difficult to compare results and set optimum conditions. As a result, mechanochemistry is generally viewed as a "black box". The aim of this work is to provide some insight into mechanochemistry. Thus, a simple kinematic-kinetic approach that allows the full parametrization of mechanically induced reactions is proposed. In an analogous way to thermally activated process, it is shown that kinetic modeling can serve to parametrize and model mechanically induced reactions as a function of the milling parameters with great reliability, thereby gaining prediction capability. As a way of example, this methodology has been applied for the first time to the mechanochemical reaction of $\mathrm{Co}$ and $\mathrm{Sb}$ to form $\mathrm{CoSb}_{3}, \mathrm{a}$ skutterudite-type thermoelectric material. Moreover, the universality of this methodology has also been validated with data from the literature. A key feature of the proposed kinematickinetic approach is that it can be extrapolated to other mechanically induced reactions, either inorganic or organic.
\end{abstract}


Keywords: mechanical alloying, mechanochemical processing, kinetics, intermetallics, thermoelectric, X-ray diffraction.

\section{Introduction}

Mechanochemistry is the branch of chemistry which is related to chemical and physicochemical transformation of substances in all states of aggregation produced by the effect of mechanical energy [1]. It has attracted much attention in the last few years, with a rapid growth in the number of publications in the last decades [2-5]. This is mainly due to its unique features, which have considerable advantages over traditional synthetic procedures. For instance, the solvent-free condition is a key feature, as mechanochemistry is normally a dry process where solvents are usually not needed [6-8]. Therefore, this methodology is safer and more environmentally friendly than traditional wet chemical methods, which produce considerable amount of toxic and harmful by-products [9]. Moreover, it is possible to obtain metastable phases such as supersaturated solid solutions, due to the extension of solubility limit, crystalline and quasicrystalline intermediate phases, which can be tricky to prepare by other synthesis methods [10-17]. High-temperature chemical reactions can thereby be induced at room temperature and, generally, the resulting materials are nanostructured, homogeneously distributed with high reactivity and sinterability due to the accumulation of defects and the fresh surface area created during the milling process $[13,18,19]$. Additionally, it is a versatile and simple technique which can be applied to a considerable amount of materials [20], either organic [2,21] or inorganic compounds [22,23]. Furthermore, the scaling-up to industrial production is quite straight forward, which can be beneficial for the implementation of mechanosynthesized materials into practical applications [4]. Despite these advantages and its presumed simplicity, mechanochemistry is a stochastic process that requires the optimization of a considerable number of experimental parameters in order to achieve the desired chemical composition and microstructure. For instance, the type of mill, the milling container and its dimensions, the grinding medium, milling speed, milling time, ball-to-powder weight ratio (BPR), extent to filling in the vial and milling atmosphere are some of the parameters that significantly influence the process. Moreover, how mechanical energy is transformed into chemical energy is a question that remains unclear [4,24]. Most published works pay very little attention to the effect of milling conditions on the resulting products and a large number of published papers lack a detailed description of the experimental conditions employed, thereby making very difficult the reproduction of results from lab to lab or its scale up [25-33]. 
Consequently, mechanochemistry is viewed as a "black box" system, being mechanically activated processes rarely parameterized and therefore, making very difficult to correlate the kinetics of the reaction with the milling conditions $[34,35]$. It is worthy to mention that due to the relevance of understanding the underlying mechanisms of mechanochemistry, in-situ techniques have been recently developed [36-38]. Albeit there are several experimental challenges that need to be overcome [38], these techniques obviously suppose a great advance in the field.

Understanding the mechanochemistry mechanism, including how the milling energy is transferred into chemical energy, is crucial to converting mechanochemistry into a standard synthetic methodology in Materials Science [39]. Thus, considering the advantages of mechanochemistry, as well as its importance and intense use over the last few years, the aim of this work is to propose a new methodology for the parametrization of mechanochemical reactions. To the best of our knowledge, this is the first kinematic approach that allows to correlate the milling parameters with the kinetics of the reaction, making possible the prediction of experimental curves. This new procedure is similar to those applied in thermally activated process, which has been extensively modelled in terms of temperature and extent of conversion [40-43]. Given the amount of effort that requires the optimization of milling conditions in mechanically induced reactions, we believe that the ability to parametrize and predict would constitute a powerful tool for researchers interested in mechanochemistry, catalysing, even more, its development. In order to carry out this analysis, several experimental parameters such as the dimensions of the jars, the grinding medium and the rotational speed have been explored in order to coherently vary the input power and the impact energy applied to the reactants. These two parameters as well as the accumulated energy during the milling process have been calculated according to the theoretical-empirical equations proposed by Burgio et al. [44] and subsequently modelled considering the most widely used kinetic models for solid-state reactions. Burgio's kinematic equations have been chosen because, unlike many other models [45], it is composed just by analytical equations that allow a straightforward resolution of the system. Additionally, Burgio's model has also been externally validated by other authors, who concluded that this kinematic model can certainly be used to calculate the energy transferred in high energy milling processes in planetary mills [46]. The mechanosynthesis of $\mathrm{CoSb}_{3}$ from metallic $\mathrm{Co}$ and $\mathrm{Sb}$ has been used as way of example to show the potential of this methodology for the prediction of mechanically induced reactions. $\mathrm{CoSb}_{3}$ is a compound with skutterudite type structure that has attracted some interest due to its unique features as a thermoelectric 
material [47-52]. Moreover, the universality of this methodology has been also validated with data from literature, proving that it can be used with either organic and inorganic compounds, as long as the applied impact energy is known.

\section{Experimental}

\subsection{Material synthesis and characterization}

The procedure described in previous works for the mechanosynthesis of $\mathrm{CoSb}_{3}$ has been followed [53,54]. Hence, stoichiometric amounts of Cobalt (Sigma-Aldrich, 266647, <150 $\mu \mathrm{m}$, 99,9\% in purity) and Antimony (Sigma-Aldrich, 266329, -100 mesh, 99.5\% in purity) powders were charged in stainless steels jars and milled until the reaction was finished. Two different models of planetary mills were employed: the Micro Mill Pulverisette 7 Premium Line (Fritsch, Germany) and PM100 (Retsch GmbH, Germany). Both of them have been modified so that they can work under controlled atmosphere of gases, being connected with a gas cylinder during the whole milling process [55]. All milling treatments were carried out under an atmosphere of 5 bars of pure nitrogen in order to avoid the contamination and oxidation of the compounds during the grinding process. The different milling conditions used in this work are listed in Table 1.

Table 1. Different experimental conditions

\begin{tabular}{|c|c|c|c|c|c|c|c|}
\hline $\begin{array}{c}\text { Experimental } \\
\text { conditions }\end{array}$ & $\begin{array}{c}\text { Rotational speed } \\
(\mathrm{rpm})\end{array}$ & $\begin{array}{c}\text { Jar diameter } \\
(\mathrm{mm})\end{array}$ & $\begin{array}{c}\text { Jar height } \\
(\mathrm{mm})\end{array}$ & $\begin{array}{c}\text { Ball diameter } \\
(\mathrm{mm})\end{array}$ & Ball material & $\begin{array}{c}\text { Number of } \\
\text { balls }\end{array}$ & BPR \\
\hline 1 & 500 & 46.55 & 44.7 & 6.33 & $\begin{array}{c}\text { Hardened } \\
\text { steel }\end{array}$ & 130 & $1: 20$ \\
\hline 2 & 500 & 46.55 & 44.7 & 15 & $\begin{array}{c}\text { Hardened } \\
\text { steel }\end{array}$ & 10 & $1: 20$ \\
\hline 3 & 585 & 46.55 & 44.7 & 15 & $\begin{array}{c}\text { Hardened } \\
\text { steel }\end{array}$ & 10 & $1: 20$ \\
\hline 4 & 650 & 46.55 & 44.7 & 15 & $\begin{array}{c}\text { Hardened } \\
\text { steel }\end{array}$ & 9 & $1: 20$ \\
\hline 5 & 700 & 46.55 & 44.7 & 15 & $\begin{array}{c}\text { Hardened } \\
\text { steel }\end{array}$ & 10 & $1: 20$ \\
\hline 6 & 650 & 60 & 36.08 & 15 & $\begin{array}{c}\text { Hardened } \\
\text { steel }\end{array}$ & 11 & $1: 20$ \\
\hline 7 & 700 & 46.55 & 44.7 & 15.8 & $\begin{array}{c}\text { Tungsten } \\
\text { carbide }\end{array}$ & 10 & $1: 40$ \\
\hline
\end{tabular}

For every milling treatment, small amounts of samples were routinely collected from the jars at different milling times. X-Ray diffraction (XRD) patterns were recorded with a Rigaku Miniflex diffractometer $\left(\mathrm{CuK}_{\alpha}\right.$ radiation, $\left.\lambda=0.15405 \mathrm{~nm}\right)$ working at $45 \mathrm{kV}$ and $40 \mathrm{~mA}$. 
Measurements were taken within a $2 \theta$ range from 20 to $60^{\circ}$, with a $0.02^{\circ}$ step and a scan speed of 0.24 seconds per step. Rietveld Refinements were carried out with X'Pert HighScore Plus software in order to obtain quantitative information about the phases presented during the milling treatments.

The morphology and chemical composition of the powders were studied by Scanning Electron Microscopy (SEM) using a Hitachi S-4800 SEM-FEG, equipped with an energy dispersive X-ray spectrometer (EDX), Quantax Bruker. In order to obtain the micrographs, the field-emission gun was operated at $2 \mathrm{kV}$, whereas for the EDX analysis and compositional chemical mappings it was operated at $20 \mathrm{kV}$. Due to the highly aggregated nature of the powders, which is typical of milling products, the samples had to be previously prepared prior their observation by SEM. Specifically, the powders were dispersed in absolute ethanol for 10 min in an ultrasonic bath. Then, a drop of the diluted supernatant was deposited on a carbon grid and it was dried slowly at room temperature so that all the ethanol could be evaporated.

\subsection{Kinematic analysis}

The experimental parameters included in Table 1 were carefully selected in order to coherently modify the impact energy and the power input, which were calculated employing the theoretical-empirical equations proposed by Burgio et al. [44]. Particularly, the impact energy $\left(\mathrm{J} \mathrm{hit}^{-1}\right)$ or the energy released in a hit, has been calculated using Eq. (1):

$$
\Delta E=\frac{1}{2} m_{b} W_{p}^{2}\left[\left(\frac{W_{v}}{W_{p}}\right)^{2}\left(\frac{D_{v}-d_{b}}{2}\right)^{2}\left(1-2 \frac{W_{v}}{W_{p}}\right)-2 R_{p}\left(\frac{W_{v}}{W_{p}}\right)\left(\frac{D_{v}-d_{b}}{2}\right)-\left(\frac{W_{v}}{W_{p}}\right)^{2}\left(\frac{D_{v}-d_{b}}{2}\right)^{2}\right]
$$

Where $m_{b}$ and $d_{b}$ are the mass and the diameter of a ball, $D_{v}$ is the diameter of the jars, $R_{p}$ is the distances from the centre of the mill to the centre of the vial and $W_{p}$ and $W_{v}$ are the angular velocity of the supporting disk and the jars, respectively. In the two models of planetary mills employed, the ratio of rotational speed corresponds to $W_{p}=-W_{v}$. In real systems, more than one ball contributes simultaneously to the milling process, existing a hindering effect among the balls that decreases the impact energy. Thus, taking into account the hindering factor, $\varphi_{b}$, the impact energy is corrected as follows [44]:

$$
\Delta E^{*}=\varphi_{b} \Delta E(2)
$$

The total power can be calculated from Eq. (3):

$$
P=\Delta E^{*} N f(3)
$$


$\mathrm{N}$ is the number of balls in the jars and $f$ is the frequency at which balls are launched against the opposite wall of the jars. $f$ is estimated considering the following formula:

$$
f=K \frac{W_{p}-W_{v}}{2 \pi}(4)
$$

Where $K$ is a constant related to the time necessary to dissipate the corrected impact energy $\Delta E^{*}$. Finally, the total energy transferred per unit weight of powder $\left(\mathrm{J} \mathrm{g}^{-1}\right)$ for a given milling time, $t_{M}$, can be expressed as:

$$
E_{c u m}=\frac{\Delta E^{*} N f t_{M}}{m_{p}}(5)
$$

Where $m_{p}$ is the mass of the sample in grams.

\section{Results and discussion}

\subsection{Kinematic Analysis}

Table 1 summarizes the different milling conditions employed in this work. As a way of example, the collected XRD patterns as a function of the milling time for the experimental condition 4 are shown in Figure 1. Similar trends were obtained for the rest of experimental conditions (see Figures S 1, S 7 and S 8), with the exception of condition 1, where the desired phase was not obtained. The possible causes are discussed later on. The mechanochemical reaction is considered to be over when the raw materials are totally consumed, taken the $\mathrm{Sb}$ peak at $28.7^{\circ}$ as reference. These results are analogous to those obtained in previous works, where $\mathrm{CoSb}_{3}$ was also prepared by mechanochemistry [53,54]. Details about the morphology as well as the chemical mappings as a function of the milling time can be found in Figure S 2 . As it can be inferred, powders tend to highly aggregate and compositionally homogenize, while milling proceeds.

The kinematic parameters such as the corrected impact energy, $\Delta E^{*}$, the power, $P$, and the total energy transferred to the powder per unit of weight at the end of each milling treatment, $E_{\text {cum }}$ were calculated for each experimental conditions using Equations 2, 3 and 5, respectively. These parameters alongside the milling time required for the total consumption of raw materials, $t_{M}$, are presented in Table 2 . 
Table 2. Milling time, $t_{M}(\mathrm{~min})$, corrected impact energy, $\Delta E^{*}\left(\mathrm{~J} \mathrm{hit}^{-1}\right)$, power, $\mathrm{P}(\mathrm{W})$, and total energy transferred to the powder per unit weight at the end of each milling treatment, $E_{\text {cum }}\left(\mathrm{J} \mathrm{g}^{-1}\right)$ under the experimental conditions described in Table 1.

\begin{tabular}{|c|c|c|c|c|}
\hline $\begin{array}{c}\text { Experimental } \\
\text { conditions }\end{array}$ & $t_{M}(\mathrm{~min})$ & $\begin{array}{c}\Delta E^{*} \\
\left(\mathrm{~J} \mathrm{hit}^{-1}\right)\end{array}$ & $\begin{array}{c}\mathrm{P} \\
(\mathrm{W})\end{array}$ & $E_{\text {cum }}\left(\mathrm{J} \mathrm{g}^{-1}\right)$ \\
\hline 1 & 1005 & $3.4 \cdot 10^{-3}$ & 10 & $6.3 \cdot 10^{5}$ \\
\hline 2 & 600 & 0.041 & 11 & $3.3 \cdot 10^{5}$ \\
\hline 3 & 300 & 0.056 & 16 & $2.7 \cdot 10^{5}$ \\
\hline 4 & 210 & 0.072 & 21 & $2.8 \cdot 10^{5}$ \\
\hline 5 & 190 & 0.080 & 28 & $2.9 \cdot 10^{5}$ \\
\hline 6 & 150 & 0.114 & 41 & $3.2 \cdot 10^{5}$ \\
\hline 7 & 120 & 0.157 & 55 & $3.2 \cdot 10^{5}$ \\
\hline
\end{tabular}

Several plots can be constructed to gain insight into the process kinematics. Figure 2a) and b) shows the milling time required for the total consumption of raw materials as a function of the corrected impact energy, $\Delta E^{*}$, and input power, $\mathrm{P}$, respectively, for each experimental condition included in Table 1. As it is expected, the highest the impact energy and the input power, the shorter the milling time required for the total consumption of raw materials. For instance, for the highest corrected impact energy used in this set of experiments, $0.157 \mathrm{~J} \mathrm{hit}^{-1}$, which corresponds to an input power of $55 \mathrm{~W}$, a milling time of $120 \mathrm{~min}$ is required to completely convert the reactants. On the other hand, at $\Delta E^{*}=0.041 \mathrm{~J} \mathrm{hit}^{-1}$, associated with an input power of $11 \mathrm{~W}$ a milling treatment as long as $600 \mathrm{~min}$ is needed to complete the reaction. It is noteworthy that under Condition 1, the product is not obtained even after milling for 1005 min (XRD data included Figure S1). This data point has been represented by a blue star in Figure 2, being totally displaced of the trend with respect to the other data points at which the desired phase was obtained. This deviation may be attributed to 1) the existence of a threshold value of impact energy below which the reaction does not occur or 2) simply the milling time is not long enough, accepting that the reaction can take place with milling treatments long enough regardless the supplied impact energy [56].

In order to linearize and parametrize the relationship between the corrected impact energy and the input power with the milling time required for the formation of the desired phase, the natural logarithm of the milling time against the inverse of the impact energy and the input power were represented, as it is shown in Figure 2c) and d), respectively. Excluding the data point for condition 1 (represented by a blue start in the inset of Figure 2c) and d)), because the desired phase was not obtained, the rest of the data follow a clear linear relationship, which can be parametrized according to the following expressions: 


$$
\begin{gathered}
\ln \left(t_{M}\right)=8.8 \cdot 10^{-2} \frac{1}{\Delta E^{*}}+4.19(6) \\
\ln \left(t_{M}\right)=21.08 \frac{1}{P}+4.43(7)
\end{gathered}
$$

Finally, the total energy transferred during the entire milling process per unit weight of powder $\left(\mathrm{J} \mathrm{g}^{-1}\right), E_{\text {cum }}$, was calculated according to equation 5 taking into account the milling time, $t_{M}$, required for the consumption of the raw materials. In Figure 3, $E_{\text {cum }}$ is represented as a function of the applied input power, $P$, under each experimental conditions detailed in Table 1. It is very interesting that the amount of energy required to produce a complete reaction is approximately similar regardless the input power or the impact energy used. Thus, aside from the experimental conditions $1, E_{\text {cum }}$ remains around an average value of $3.1 \cdot 10^{5} \mathrm{~J} \mathrm{~g}^{-1}$. Gotor et al. validated Burgio's kinematic equation assuming that the total amount of energy per unit weight of powder required to trigger ignition in a self-sustaining reaction should be kept constant regardless the milling condition [46]. Therefore, extrapolating this concept to the particular case of the mechanochemical reaction of $\mathrm{CoSb}_{3}$, the constant value of $E_{c u m}$ for every experimental condition corroborates once again Burgio's kinematic equation to calculate the energy transferred in planetary mill. Additionally, it is also noteworthy that the specific energy needed for the formation of $\mathrm{CoSb}_{3}$ by mechanical alloying is considerably higher than that predicted thermodynamically [53]. Nevertheless, that can be easily explained by the substantial amount of energy released in form of heat and expended in disordering the structure [5,57]. Just a small fraction of this energy is actually absorbed by the small quantity of powders trapped in the collisions [58].

Thus, by this kinematic analysis we have shown that it is possible to parametrize by simple logarithmic equations the relationship between the milling time, $t_{M}$, the reverse of the corrected impact energy, $1 / \Delta E^{*}$, and the input power, $1 / \mathrm{P}$. Additionally, the total energy transferred per unit weight of powder $\left(\mathrm{J} \mathrm{g}^{-1}\right), E_{\text {cum }}$, at the end of the each mechanical treatment is approximately the same under each experimental condition tested, which validates Burgio's kinematic equations as stated above.

\subsection{Kinetic Modelling of the mechanochemical reaction}

As a step further from this kinematic analysis, experimental conditions 2, 4, 6 and 7 (Table 1) were selected to carry out a thorough kinetic analysis of the mechanically induced formation 
of $\mathrm{CoSb}_{3}$, with the aim of determining the underlying reaction mechanism and the kinetic parameters describing the reaction. Thus, a step-by-step analysis of the transformation of raw materials $(\mathrm{Co}+\mathrm{Sb})$ into the reaction products as a function of the milling time was performed. The degree of conversion was defined as follows:

$$
\alpha=1-\frac{S b_{t_{i}}(\%)}{S b_{t_{1}}(\%)}(8)
$$

Where $S b_{t_{1}}(\%)$ and $S b_{t_{i}}(\%)$ are the weight fraction of antimony determined by Rietveld refinements of the XRD data at the beginning and at a given time, $t_{i}$, of the mechanochemical reaction, respectively. Figure S 3 contains Rietveld refinements at different milling times for experimental conditions 6 , as a way of example. It is worth noting that this definition of the degree of conversion, $\alpha$, is possible because the raw materials are progressively transformed into products. Nevertheless, there are many cases, where intermediate compounds are formed, e.g. in the mechanochemical reaction of $\mathrm{Bi}_{2} \mathrm{O}_{3}$ and $\mathrm{Fe}_{2} \mathrm{O}_{3}$ into $\mathrm{BiFeO}_{3}, \mathrm{Bi}_{25} \mathrm{FeO}_{39}$ is formed prior the final product [55]. Those kinds of cases deserve special attention and further research is needed, as they required a different definition of $\alpha$, which probably involves a complex kinetic with several steps or even independent processes.

Figure 4 shows the $\alpha$ values calculated from Eq. (8) as a function of the milling time, $t_{M}$, for the experimental conditions 2, 4, 6 and 7 (Table 1), which correspond to a corrected impact energy, $\Delta E^{*}$, of $0.041,0.072,0.114$ and $0.157 \mathrm{~J} \mathrm{hit}^{-1}$, respectively. It is worthy to note that these kinds of ex-situ stepwise analysis are possible because the reaction is not affected by the milling stops and continuous milling or segmented milling yield to the same final products, unlike other cases where different products are obtained depending on the continuity of the milling treatment [59].

The $\alpha$ - milling time curves are shifted to higher milling times as the applied corrected impact energy decreases. This phenomenon is much more pronounced for the lowest impact energy $\left(0.041 \mathrm{~J} \mathrm{hit}^{-1}\right)$. Thus, for every milling condition, there is an onset time (or accumulated onset energy) required for the reaction to start, which seems to be inversely proportional to the applied impact energy. These kind of induction periods are quite common in mechanically induced reactions $[46,60]$ and for every experimental condition included in Figure 4, this onset time, $t_{0}$, was estimated according to the procedure shown in Figure S 4 (only for conditions 2 , as a way of example) and represented as a function of the impact energy (Figure S 5a)). It can be observed that the minimum milling time clearly decreases with the impact energy. Moreover, as it is shown in Figure $\mathrm{S} 5 \mathrm{~b}$ ), the logarithm of $\mathrm{t}_{0}$ versus the reverse of the corrected impact 
energy also follows a linear relationship, similar to equation 6 , that can be described with the following expression:

$$
\ln \left(t_{0}\right)=0.096 \frac{1}{\Delta E^{*}}+3.02(9)
$$

Additionally, the total energy transferred per unit weight of powder $\left(\mathrm{J} \mathrm{g}^{-1}\right)$ considering these minimum milling times, $t_{0}$, for every experimental condition included in Figure 4, was calculated using Eq. (5). Interestingly, the energy transferred per unit weight does not depend on the milling conditions and it is approximately the same for every experimental condition, which value is $1.1 \pm 0.1 \cdot 10^{5} \mathrm{~J} \mathrm{~g}^{-1}$. It has been claimed that the induction periods of mechanically induced reactions are the result of a two-step process, where mass transport plays an initial important roll and then the mechanical energy is accumulated in the form of structural defects and heat within other forms of energy that eventually can exponentially trigger the chemical reaction [60]. However, besides this accumulated onset energy, the minimum impact energy also plays a critical role in the induction of the reaction, as it was discussed above for experimental condition 1. This is in agreement with the conclusion of Fischer et al. who stated that the input energy of a single collision has greater influence on the kinetics of the reaction than the number of collisions or, in other words, the milling frequency [56]. This is to say that not only the accumulated onset energy is the limiting factor to trigger a mechanically induced reaction but also the threshold value of impact energy. Thus, as a way of summary, we can conclude that when the threshold value of impact energy is exceeded, the accumulated onset value of energy for the reaction to start remains approximately constant regardless the milling conditions and below which the mechanically induced reaction cannot start.

In order to get more information about the underlying mechanism of the mechanically induced reaction of $\mathrm{CoSb}_{3}$, a kinetic analysis of the curves included in Figure 4 was carried out. Traditionally, the kinetics of mechanochemical reactions have been described with first-order or sigmoid functions [45,61], but it may be interesting to consider other options [36]. Thus, we decided to consider the most widely used kinetic models for solid state processes and proceed in an analogous way to the analysis performed in thermally activated processes. As we explain as follows, this procedure has the advantage that the reaction rate constant can be described as a function of the milling parameters, unlike in many other previous published works $[36,62]$. This allows to extrapolate a mechanically induced reaction to other different milling conditions, easing the reproducibility from lab to lab, even when different milling devices are used. 
Moreover, this procedure also allows to validate the chosen kinetic model as well as gaining prediction capability.

The kinetic analysis of the curves included in Figure 4 was carried out considering the general kinetic equation widely used for the reaction rate of a solid-state process:

$$
\frac{d \alpha}{d t}=k f(\alpha)
$$

where $\alpha$ is the degree of conversion (defined according to equation 8 ), $d \alpha / d t$ is the reaction rate, $f(\alpha)$ is an algebraic equation usually associated with a physical model that describes the kinetics of the solid-state process and $k$ is the rate constant that is usually defined by an Arrhenius expression. According to Butyagin, the term of temperature in the Arrhenius expression can be substituted by rate of supplied energy in mechanically activated process [63]. Thus, $k$ can be defined as:

$$
k=A e^{-\frac{\beta}{\Delta E^{*}}}
$$

Where $A$ is the pre-exponential factor analogously to thermally activated processes, also associated with the frequency of collisions in a mechanically induced process, $\Delta E^{*}$ is the corrected impact energy at which the mechanochemical treatment is being processed and $\beta$ is a parameter which is dimensionally equal to the corrected impact energy. Albeit in extreme simplification, $\beta$ has been defined as the difference of activation energy of the chemical reaction and the total energy accumulated in the system in a mechanochemical process. Unfortunately, this two parameters cannot be assessed separately [60].

In mechanically induced reactions carried out under certain experimental conditions, the corrected impact energy, $\Delta E^{*}$, is normally constant during the whole process. Therefore, $k$ (Eq. (11)) remains constant and Eq. (10) can be integrated:

$$
\int_{0}^{\alpha} \frac{d \alpha}{f(\alpha)}=k \int_{0}^{t} d t
$$

Equation (12) can be also expressed as:

$$
g(\alpha)=k t
$$

The plot of $g(\alpha)$ versus the process time for the experimental curves provides straight lines if the selected kinetic model is correct, and the slope of these lines corresponds to the rate constant, $k$, for every experiment performed at fixed values of $\Delta E^{*}$. Kinetic $\mathrm{f}(\alpha)$ and $\mathrm{g}(\alpha)$ functions corresponding to the most used kinetic models are shown in Table 3. 
Table 3. Kinetic $f(\alpha)$ and $g(\alpha)$ functions corresponding to the most used kinetic models.

\begin{tabular}{|c|c|c|c|}
\hline Mechanism & Symbol & $f(\alpha)$ & $\mathbf{g}(\alpha)$ \\
\hline First order & $\mathrm{F} 1$ & $(1-\alpha)$ & $-\ln (1-\alpha)$ \\
\hline $\begin{array}{l}\text { Phase boundary controlled } \\
\text { reaction (contracting area) }\end{array}$ & $\mathrm{R} 2$ & $(1-\alpha)^{1 / 2}$ & $2\left[1-(1-\alpha)^{1 / 2}\right]$ \\
\hline $\begin{array}{c}\text { Phase boundary controlled } \\
\text { reaction (contracting } \\
\text { volume) }\end{array}$ & R3 & $(1-\alpha)^{2 / 3}$ & $3\left[1-(1-\alpha)^{1 / 3}\right]$ \\
\hline $\begin{array}{l}\text { Random nucleation and } \\
\text { growth of nuclei through } \\
\text { different nucleation and } \\
\text { nucleus growth models } \\
\text { (Avrami-Erofeev eq. } n \neq 1 \text { ) }\end{array}$ & An & $n(1-\alpha)[-\ln (1-\alpha)]^{1-\frac{1}{n}}$ & {$[-\ln (1-\alpha)]^{\frac{1}{n}}$} \\
\hline Two-dimensional diffusion & D2 & $1 /[-\ln (1-\alpha)]$ & $(1-\alpha) \ln (1-\alpha)+\alpha$ \\
\hline $\begin{array}{l}\text { Three-dimensional } \\
\text { diffusion (Jander eq.) }\end{array}$ & D3 & $3(1-\alpha)^{2 / 3} /\left[2\left(1-(1-\alpha)^{\frac{1}{3}}\right)\right]$ & {$\left[\left(1-(1-\alpha)^{\frac{1}{3}}\right)\right]^{2}$} \\
\hline $\begin{array}{l}\text { Three-dimensional } \\
\text { diffusion (Ginstling- } \\
\text { Brounshtein eq.) }\end{array}$ & D4 & $3 /\left[2\left((1-\alpha)^{-1 / 3}-1\right)\right]$ & $\left(1-2 \frac{\alpha}{3}\right)-(1-\alpha)^{\frac{2}{3}}$ \\
\hline
\end{tabular}

For the selected milling conditions represented in Figure 4, the plots of $g(\alpha)$ versus milling time, $t_{M}$, (Eq. (13)) were built assuming some of the most used kinetic models for $f(\alpha)$ (listed in Table 3), such as interface controlled (R2, R3), random nucleation and growth of nuclei or Avrami-Erofeev (A1, A2, A3, A4), and two-dimensional and three-dimensional diffusion controlled (D2, D3).

The best linear fits to the plots were obtained for the interface controlled kinetic models, and particularly for the R3 kinetic model, which means that nucleation is not kinetically relevant in the formation of mechanically induced $\mathrm{CoSb}_{3}$. Figure 5a) shows the linear fits obtained for every mechanical treatment performed at constant values of corrected impact energy, considering the R3 kinetic model. From the slopes of these fits, the rate constant, $k$, for every experimental condition was obtained.

Given the Arrhenius dependence of $k$ and rearranging Eq. (11) in logarithmic form, equation (14) is obtained:

$$
\ln k=\ln A-\frac{\beta}{\Delta E^{*}}
$$


The pre-exponential factor, $A$, can be obtained from the intercept of the plot of the logarithm of the rate constant versus the reverse of their corresponding corrected impact energy, $\Delta E^{*}$, while $\beta$ can be calculated from the slope of such plot. Figure $5 b)$ presents the plot of $\ln (k)$ versus the inverse of $\Delta E^{*}$, being the values of $\beta$ and $A 0.061 \mathrm{~J} \mathrm{hit}^{-1}$ and $0.033 \mathrm{~min}^{-1}$, respectively. Thus, this method parametrizes the rate constant based on the impact energy, which can be easily calculated as a function of the milling parameters by using a simple analytical expression (Equation 2). We would like to remark that the proposed methodology goes beyond a mere phenomenological characterization of the rate constant, allowing the full correlation between the kinetic of the reaction and the milling conditions. Conversely to many other previous kinetic models [36,57,62], this model takes into account milling parameters such as the mass, diameter and number of balls, diameter of the jars, the angular velocity of the supporting disk and the jars and the frequency of impact. This allows to easily extrapolate and reproduce the mechanochemical results from lab to lab even when different planetary mills are used.

Moreover, in order to validate the value of $\beta$, an integral isoconversional method was applied [64]. The foundations of the isoconversional methods in mechanically induced reactions rely on the fact that the reaction rate exclusively depends on the impact energy at a constant extent of conversion, $\alpha$, in an analogous way to classical isoconversional methods in thermally activated processes. These kinds of methods allow the determination of the parameter $\beta$ as a function of the degree of conversion, $\alpha$, from a set of $\alpha$-time plots recorded at different impact energies, without any previous assumption of the kinetic model. Assuming that the mechanochemical treatment is carried out under strict conditions of constant impact energy, Eq. (13) can be rearranged in logarithmic form:

$$
\ln (t)=\ln (g(\alpha))-\ln A+\frac{\beta}{\Delta E^{*}}(15)
$$

This last assumption is reasonable, as based on Equations (6) and (7), under specific experimental conditions, the milling parameters are prefixed, giving constant values of impact energy. Moreover, Eq. (15) also assumes that the extent of conversion dependence of the reaction rate obeys some of the proposed solid-state kinetic models $(f(\alpha)$ and, therefore, $g(\alpha)$ functions), although it is not absolutely necessary. Finally, the last prerequisite to use Eq. (15) is that the process must follow a simple kinetic, i.e. a single-step process, implying that $\beta$ must be independent of $\alpha$ and it must remain constant throughout the whole interval of degree of conversion. Otherwise, the process should be treated as kinetically-complex and Eq. (15) cannot be directly applied [65]. If those conditions are accomplished, at a particular value of $\alpha$, 
$\ln (g(\alpha))$ as well as $\ln A$ are constant. Therefore, the parameter $\beta$ can be determined, as a function of the degree of conversion, from the slope of the left-hand side of Eq. (15), $\ln (t)$, versus the inverse of the corrected impact energy (Figure S 6). Figure 6 represents the values of $\beta$ as a function of the degree of conversion obtained from this isoconversional method. It can be observed that $\beta$ values are approximately constant in the entire range of $\alpha$ with an average value of $0.082 \mathrm{~J} \mathrm{hit}^{-1}$ and in relatively good agreement with that obtained when the kinetic model is previously assumed, proving the reliability of the $\beta$ parameter. To the best of our knowledge, this isoconversional procedure has never been applied to mechanically induced reactions before and can be extremely useful to validate the kinetic model, as long as the prerequisites exposed above are met.

Additionally, the accuracy of the kinetic parameters, $A$ and $\beta$, obtained from Eq. (14), was tested comparing the experimental curves in Figure 4 with simulated kinetic curves constructed using these parameters, the corrected impact energy at which each mechanical treatment was performed, $\Delta E^{*}$, the corresponding minimum milling time, $\mathrm{t}_{0}$, at which the reaction starts and the R3 kinetic model. The simulations were carried out by integrating the general kinetic equation (Eq. (10)) and using the fourth-order numerical integration Runge-Kutta method. As it is shown in Figure 4, the simulated and experimental curves are in very good agreement, which proves the validity of the kinetic parameters obtained by this methodology for mechanically induced reactions. Therefore, we not only propose a kinematic analysis of a mechanically induced reaction that is a function of the most important experimental parameters influencing the kinetics of the mechanically induced reactions but also a methodology that allows to double check the reliability of the obtained kinematic parameters that for the first time goes beyond the traditional simulations of the experimental curves.

\subsection{Prediction capability}

As a step further to prove the validity of the proposed model, the kinetic parameters obtained from the analysis were used to predict the behaviour of the process under experimental conditions not employed in the analysis. Thus, conversion-time curves were predicted and plotted in Figure 7 as solid lines for experimental conditions 3 and 5, taking into account the R3 kinetic mode and the calculated kinetic parameters $\left(\beta=0.061 \mathrm{~J} \mathrm{hit}^{-1}\right.$ and $\left.A=0.033 \mathrm{~min}^{-1}\right)$. The minimum milling time at which the reaction should start was established by Eq. (9). Then, the prediction was validated experimentally. XRD data were collected very close to the 
predicted minimum milling time at which the reactions should start. These experimental data are marked as (1) and (4) in Figure 7. As it was predicted from the simulated curves and as it can be inferred from the XRD patterns (Figure S 7 (1), S 8 (4)), at such milling times the mechanical transformation of the raw materials into products has not started yet, being the degree of conversion $\alpha$ equal to 0 . Additionally, XRD patterns under both experimental conditions were also collected at higher milling times. It can be observed that these experimental data (Figure S $7(2,3)$ and S $8(5,6))$ marked as (2), (3), (5) and (6) in Figure 7 are in total agreement with the predicted curves. Hence, this simple kinematic-kinetic analysis is able to predict experimental curves, validating once again the proposed model. In light of these results, we would like to emphasize that the joined analysis of several experimental curves obtained under different milling conditions allows the full parametrization of mechanically induced reactions, gaining prediction capability, which offers a unique opportunity to quantitatively correlate the effect of the most important milling parameters on the kinetics of the reaction. Previous reports have attempted to analyse the kinetics of mechanochemical processes but just considering one $\alpha$-time curve, which does not allow to fully parametrize the system, validate the proposed kinetic model or make predictions at all [62].

\subsection{Validation with literature data}

In order to prove the versatility and soundness of the proposed methodology, data from literature were analysed following the procedure described above. Particularly, data from reference [66] were used, where the authors described the mechanochemical reaction of 2,3diphenylquinoxaline, an organic compound of high interest [67], as a function of the milling frequency on a vibratory shaker ball mill. The impact energy at each frequency was calculated by the classical equations of motion, considering an oscillation amplitude of $19.5 \mathrm{~mm}$ and a lineal trajectory of the ball along the milling jar. Table 4 contains the proposed kinetic models and parameters, which can reproduce the experimental data at each milling frequency with great reliability, as it is shown in Figure 8. It is worthy to note that the reaction kinetics follow different regimes depending on the milling frequency. At high frequencies $(30-25 \mathrm{~Hz})$, the kinetic can be described by A2 mechanism where nucleation is kinetically relevant, whereas at low frequency $(22.5-20 \mathrm{~Hz})$, the kinetics follows a zero-order relationship. As the authors claimed, it may be attributed to the differences in the mechanical energy provided to the material. At lower frequencies rolling and shearing are favoured, while at higher frequency more energetic impacts are given, which lead to the creation of more active sites [66]. A similar 
behaviour has been observed for some thermally activated processes, where different kinetic mechanisms have been reported for low and high temperatures [68].

All in all, we have proved that the proposed methodology for modelling mechanochemical reactions is a universal procedure which can be applied to either organic or inorganic compounds, as along as the applied impact energy can be calculated. It allows the description of mechanically induced reaction regardless the experimental set up or milling conditions, which aims to convert mechanochemistry in a convectional synthetic procedure in Materials Science.

Table 4. Reaction, type of mill and kinetic model and parameters obtained from the analysis of the experimental data of reference [66].

\begin{tabular}{|c|c|c|c|c|c|c|}
\hline Reaction & Type of mill & $\begin{array}{c}\text { Frequency } \\
(\mathrm{Hz})\end{array}$ & $\begin{array}{c}\text { Impact } \\
\text { Energy }(\mathrm{J} \\
\left.\mathrm{hit}^{-1}\right)\end{array}$ & $\begin{array}{c}\text { Kinetic } \\
\text { Model }\end{array}$ & $A\left(\mathrm{~min}^{-1}\right)$ & $\beta\left(\mathrm{J} \mathrm{hit}^{-1}\right)$ \\
\hline 2,3-diphenylquinoxaline \\
$\begin{array}{c}\text { (benzyl+ortho- } \\
\text { phenylenediamine) }\end{array}$ & $\begin{array}{c}\text { MM400 } \\
\text { (Retsch) }\end{array}$ & $22.5-20$ & $\begin{array}{c}1.18 \cdot 10^{-3}- \\
9.31 \cdot 10^{-4}\end{array}$ & Zero-Order & $2.3 \cdot 10^{-3}$ & 0.154 \\
\cline { 3 - 7 } & & & A2 & $2.15 \cdot 10^{-3} \pm 5 \cdot 10^{-4}$ & $0.376 \pm 1 \cdot 10^{-2}$ \\
\hline
\end{tabular}

\section{Conclusions}

Nowadays, mechanochemistry has attracted a lot of attention with a rapid growth in the number of publications due to its unique features. Nevertheless, very little is known about how mechanical energy is converted into chemical energy or how the experimental parameters affect the resulting products. Mechanochemical processes are reconsidered, in most of the cases, as "black boxes". Unfortunately, this hinders a proper understanding of the mechanically induced reaction dynamics, which remain highly elusive and slows down the development of mechanochemistry.

Here, we propose a new methodology that allows the full parametrization of a mechanically induced reaction as a function of the milling parameters by applying simple analytical equations, gaining prediction capability and easing the reproducibility of results from lab to lab. It is proven that the joined analysis by this methodology of several experimental curves obtained under different milling conditions, yields to highly reliable kinetic parameters. This allows to 
describe and, even more important, predict mechanically induced reactions. Additionally, the validation of the kinetic parameters is also possible by applying an isoconversional methodology, widely used in thermally activated processes, as well as by simulating the experimental curves. To the best of our knowledge, this is the first time that the isoconversional analysis is applied to mechanically induced reactions.

Finally, we would like to emphasize, once again, that the proposed methodology goes beyond a mere phenomenological description of a mechanically induced reaction, as it quantitatively correlates the milling parameters, including the geometry of the mill, jars and mass and number of balls, with the dynamics of the chemical reaction. Moreover, the universality of this methodology have been also validated, proving that it can be applied to either inorganic and organic compounds, as long as the applied impact energy is known. Therefore, mechanically induced reaction should be described as a function of the applied impact energy, which would allow to predict results regardless the experimental set up and conditions. Thus, we believe that this methodology offers a unique opportunity to catalyze the progress in the field of mechanochemistry and convert it into a conventional synthetic method in Materials Science.

\section{Acknowledgements}

This work has been supported by the Spanish Government Agency Ministerio de Economía y Competitividad and FEDER (project CTQ2017-83602-C2-1-R) and by Junta de AndalucíaConsejería de Economía, Conocimiento, Empresas y Universidad and FEDER (projects P18FR-1087 and US-1262507). Financial support from project 201960E092 (INTRAMURALCSIC) is also acknowledged.

\section{Bibliography}

[1] M. Petruschke, Tribochemistry. von G. HEINICKE. Berlin: Akademie-Verlag 1984. Bestellnummer: 7631993(6746). 495 S., 329 Bilder, 106 Tabellen, 98,- M, Acta Polym. 36 (1985) 400-401. https://doi.org/10.1002/actp.1985.010360721.

[2] J. Andersen, J. Mack, Mechanochemistry and organic synthesis: from mystical to practical, Green Chem. 20 (2018) 1435-1443. https://doi.org/10.1039/C7GC03797J.

[3] S.L. James, C.J. Adams, C. Bolm, D. Braga, P. Collier, T. Friščić, F. Grepioni, K.D.M. Harris, G. Hyett, W. Jones, A. Krebs, J. Mack, L. Maini, A.G. Orpen, I.P. Parkin, W.C. Shearouse, J.W. Steed, D.C. Waddell, Mechanochemistry: opportunities for new and cleaner synthesis, Chem. Soc. Rev. 41 (2012) 413-447. https://doi.org/10.1039/C1CS15171A. 
[4] P. Baláž, M. Achimovičová, M. Baláž, P. Billik, Z. Cherkezova-Zheleva, J.M. Criado, F. Delogu, E. Dutková, E. Gaffet, F.J. Gotor, R. Kumar, I. Mitov, T. Rojac, M. Senna, A. Streletskii, K. Wieczorek-Ciurowa, Hallmarks of mechanochemistry: from nanoparticles to technology, Chem. Soc. Rev. 42 (2013) 7571-7637. https://doi.org/10.1039/C3CS35468G.

[5] L. Takacs, The historical development of mechanochemistry, Chem. Soc. Rev. 42 (2013) 7649 7659. https://doi.org/10.1039/C2CS35442J.

[6] G.N. Hermann, P. Becker, C. Bolm, Mechanochemical Iridium(III)-Catalyzed C-H Bond Amidation of Benzamides with Sulfonyl Azides under Solvent-Free Conditions in a Ball Mill, Angew. Chemie Int. Ed. 55 (2016) 3781-3784. https://doi.org/10.1002/anie.201511689.

[7] A.L. Garay, A. Pichon, S.L. James, Solvent-free synthesis of metal complexes., Chem. Soc. Rev. 36 (2007) 846-855. https://doi.org/10.1039/b600363j.

[8] A. Pichon, A. Lazuen-Garay, S.L. James, Solvent-free synthesis of a microporous metal-organic framework, CrystEngComm. 8 (2006) 211-214. https://doi.org/10.1039/B513750K.

[9] W.C. Shearouse, D.C. Waddell, J. Mack, Alternative solvent-free methodologies in the synthesis of pharmaceutical drugs., Curr. Opin. Drug Discov. Devel. 12 (2009) 772-783.

[10] S. Bid, S.K. Pradhan, Preparation of zinc ferrite by high-energy ball-milling and microstructure characterization by Rietveld's analysis, Mater. Chem. Phys. 82 (2003) 27-37. https://doi.org/10.1016/S0254-0584(03)00169-X.

[11] E. Nunes, E.C. Passamani, C. Larica, J.C.C. Freitas, A.Y. Takeuchi, E. Baggio-Saitovitch, A.C. Doriguetto, A.A.R. Fernandes, Extended solubility in non-equilibrium $\mathrm{Pb} / \mathrm{Fe}$ system, Mater. Sci. Eng. A. 390 (2005) 13-18. https://doi.org/10.1016/j.msea.2004.05.032.

[12] U.K. Bhaskar, S.K. Pradhan, Mechanosynthesis of nanocrystalline $\mathrm{Ti}_{0.9} \mathrm{C}_{0.1} \mathrm{~N}$ at room temperature and its microstructural aspects, Mater. Sci. Eng. A. 534 (2012) 400-407. https://doi.org/https://doi.org/10.1016/j.msea.2011.11.086.

[13] R. Ren, Z. Yang, L.L. Shaw, Polymorphic transformation and powder characteristics of $\mathrm{TiO}_{2}$ during high energy milling, J. Mater. Sci. 35 (2000) 6015-6026. https://doi.org/10.1023/A:1026751017284.

[14] J. Aufrecht, A. Leineweber, J. Foct, E.J. Mittemeijer, The structure of nitrogen-supersaturated ferrite produced by ball milling, Philos. Mag. 88 (2008) 1835-1855. https://doi.org/10.1080/14786430802322198.

[15] V. V Cherdyntsev, S.D. Kaloshkin, V.N. Serdyukov, I.A. Tomilin, E. V Shelekhov, Kinetics of mechanical alloying in the immiscible system $\mathrm{Cu}_{50} \mathrm{Cr}_{50}$, Phys. Met. Metallogr. 97 (2004) 392 398. 10.1016/S0032-5910(99)00175-8.

[16] J.M. Loureiro, B.F.O. Costa, G. Le Caër, Mechanosynthesis of supersaturated solid solutions of $\mathrm{Sn}$ in near-equiatomic bcc FeCo, J. Alloys Compd. 536 (2012) S31-S34. https://doi.org/10.1016/j.jallcom.2011.12.036.

[17] J.M. Loureiro, B.F.O. Costa, B. Malaman, G. Le Caër, S. Das, V.S. Amaral, Formation stages of bcc $\left(\mathrm{Fe}_{44} \mathrm{Co}_{44}\right) \mathrm{Sn}_{12}$ extended solid solution by mechanical alloying, J. Alloys Compd. 615 (2014) S559-S563. https://doi.org/10.1016/j.jallcom.2013.12.071.

[18] M.A. Roldán, M.D. Alcalá, C. Real, Mechanically induced self-propagating reaction of vanadium carbonitride, Ceram. Int. 41 (2015) 4688-4695. https://doi.org/10.1016/j.ceramint.2014.12.016.

[19] B.S.B. Reddy, K. Das, S.K. Pabi, S. Das, Mechanical-thermal synthesis of $\mathrm{Al}-\mathrm{Ce} / \mathrm{Al}_{2} \mathrm{O}_{3}$ nanocomposite powders, Mater. Sci. Eng. A. 445-446 (2007) 341-346. https://doi.org/10.1016/j.msea.2006.09.045.

[20] E. Boldyreva, Mechanochemistry of inorganic and organic systems: what is similar, what is different?, Chem. Soc. Rev. 18 (2013) 7719-7738. https://doi.org/10.1039/c3cs60052a. 
[21] M.K. Beyer, H. Clausen-Schaumann, Mechanochemistry: The Mechanical Activation of Covalent Bonds, Chem. Rev. 105 (2005) 2921-2948. https://doi.org/10.1021/cr030697h.

[22] V. Šepelák, A. Düvel, M. Wilkening, K.-D. Becker, P. Heitjans, Mechanochemical reactions and syntheses of oxides, Chem. Soc. Rev. 42 (2013) 7507-7520. https://doi.org/10.1039/C2CS35462D.

[23] V. Šepelák, S. Bégin-Colin, G. Le Caër, Transformations in oxides induced by high-energy ballmilling, Dalt. Trans. 41 (2012) 11927-11948. https://doi.org/10.1039/C2DT30349C.

[24] C. Suryanarayana, Mechanical alloying and milling, Prog. Mater. Sci. 46 (2001) 1-184. https://doi.org/10.1016/S0079-6425(99)00010-9.

[25] L. Kegao, Z. Jiuxing, X. Dong, The exploration for synthesizing $\mathrm{CoSb}_{3}$ powder by mechanical alloying, J. Mater. Process. Technol. $184 \quad$ (2007) 257-260. https://doi.org/10.1016/j.jmatprotec.2006.11.048.

[26] A. Fahami, R. Ebrahimi-Kahrizsangi, B. Nasiri-Tabrizi, Mechanochemical synthesis of hydroxyapatite/titanium nanocomposite, Solid State Sci. 13 (2011) 135-141. https://doi.org/10.1016/j.solidstatesciences.2010.10.026.

[27] J. Ni, J. Li, W. Luo, Q. Han, Y. Yin, Z. Jia, B. Huang, C. Hu, Z. Xu, Microstructure and properties of in-situ TiC reinforced copper nanocomposites fabricated via long-term ball milling and hot pressing, J. Alloys Compd. 755 (2018) 24-28. https://doi.org/10.1016/j.jallcom.2018.04.327.

[28] X. Su, J. Zhang, H. Mu, J. Zhao, Z. Wang, Z. Zhao, C. Han, Z. Ye, Effects of etching temperature and ball milling on the preparation and capacitance of $\mathrm{Ti}_{3} \mathrm{C}_{2}$ MXene, J. Alloys Compd. 752 (2018) 32-39. https://doi.org/10.1016/j.jallcom.2018.04.152.

[29] S. Kamrani, D. Penther, A. Ghasemi, R. Riedel, C. Fleck, Microstructural characterization of Mg-SiC nanocomposite synthesized by high energy ball milling, Adv. Powder Technol. 29 (2018) 1742-1748. https://doi.org/10.1016/j.apt.2018.04.009.

[30] A. Mebrek, S. Alleg, S. Benayache, M. Benabdeslem, Preparation and characterization of spinel type $\mathrm{Zn}_{2} \mathrm{TiO}_{4}$ nanocomposite, Ceram. Int. 44 (2018) 10921-10928. https://doi.org/10.1016/j.ceramint.2018.03.153.

[31] P.M. Jardim, M.O.T. da Conceição, M.C. Brum, D.S. dos Santos, Hydrogen sorption kinetics of ball-milled $\mathrm{MgH}_{2}-\mathrm{TiO}_{2}$ based 1D nanomaterials with different morphologies, Int. J. Hydrogen Energy. 40 (2015) 17110-17117. https://doi.org/10.1016/j.ijhydene.2015.06.172.

[32] H.N. Tien, S.H. Hur, Synthesis of highly durable sulfur doped graphite nanoplatelet electrocatalyst by a fast and simple wet ball milling process, Mater. Lett. 161 (2015) 399-403. https://doi.org/10.1016/j.matlet.2015.08.139.

[33] H. Nagano, I. Taniguchi, Synthesis of $\mathrm{Li}_{2} \mathrm{FeP}_{2} \mathrm{O}_{7} /$ Carbon nanocomposite as cathode materials for Li-ion batteries, J. Power Sources. 298 (2015) 280-284. https://doi.org/10.1016/j.jpowsour.2015.08.068.

[34] C. Mochales, H. El Briak-BenAbdeslam, M.P. Ginebra, A. Terol, J.A. Planell, P. Boudeville, Dry mechanochemical synthesis of hydroxyapatites from DCPD and $\mathrm{CaO}$ : influence of instrumental parameters on the reaction kinetics, Biomaterials. 25 (2004) 1151-1158. https://doi.org/10.1016/j.biomaterials.2003.08.002.

[35] F. Miani, P. Matteazzi, D. Basset, Mechanosynthesis of iron carbides at composition $\mathrm{Fe}_{75} \mathrm{C}_{25}$ : modeling of the process kinetics, J. Alloys Compd. 204 (1994) 151-156. https://doi.org/10.1016/0925-8388(94)90084-1.

[36] T. Friščić, I. Halasz, P.J. Beldon, A.M. Belenguer, F. Adams, S.A.J.J. Kimber, V. Honkimäki, R.E. Dinnebier, Real-time and in situ monitoring of mechanochemical milling reactions, Nat. Chem. 5 (2013) 66-73. https://doi.org/10.1038/nchem.1505.

[37] F. Fischer, K.-J. Wenzel, K. Rademann, F. Emmerling, Quantitative determination of activation 
energies in mechanochemical reactions, Phys. Chem. Chem. Phys. 18 (2016) 23320-23325. https://doi.org/10.1039/C6CP04280E.

[38] A.A.L. Michalchuk, I.A. Tumanov, S. Konar, S.A.J. Kimber, C.R. Pulham, E. V Boldyreva, Challenges of Mechanochemistry: Is In Situ Real-Time Quantitative Phase Analysis Always Reliable? A Case Study of Organic Salt Formation, Adv. Sci. 1700132 (2017). https://doi.org/10.1002/advs.201700132.

[39] D. Tan, F. García, Main group mechanochemistry: from curiosity to established protocols, Chem. Soc. Rev. 48 (2019) 2274-2292. https://doi.org/10.1039/C7CS00813A.

[40] S. Vyazovkin, A.K. Burnham, J.M. Criado, L.A. Pérez-Maqueda, C. Popescu, N. Sbirrazzuoli, ICTAC Kinetics Committee recommendations for performing kinetic computations on thermal analysis data, Thermochim. Acta. 520 (2011) 1-19. https://doi.org/10.1016/j.tca.2011.03.034.

[41] S. Vyazovkin, N. Sbirrazzuoli, Isoconversional Kinetic Analysis of Thermally Stimulated Processes in Polymers, Macromol. Rapid Commun. 27 (2006) 1515-1532. https://doi.org/10.1002/marc.200600404.

[42] S. Vyazovkin, C.A. Wight, Model-free and model-fitting approaches to kinetic analysis of isothermal and nonisothermal data, Thermochim. Acta. 340-341 (1999) 53-68. https://doi.org/10.1016/S0040-6031(99)00253-1.

[43] E. Gil-González, A. Perejón, P.E. Sánchez-Jiménez, S. Medina-Carrasco, J. Kupčík, J. Šubrt, J.M. Criado, L.A. Pérez-Maqueda, Crystallization Kinetics of Nanocrystalline Materials by Combined X-ray Diffraction and Differential Scanning Calorimetry Experiments, Cryst. Growth Des. 18 (2018). https://doi.org/10.1021/acs.cgd.8b00241.

[44] N. Burgio, A. Iasonna, M. Magini, S. Martelli, F. Padella, Mechanical alloying of the $\mathrm{Fe}-\mathrm{Zr}$ system. Correlation between input energy and end products, Nuovo Cim. D. 13 (1991) 459-476. https://doi.org/10.1007/BF02452130.

[45] F.K. Urakaev, V. V Boldyrev, Mechanism and kinetics of mechanochemical processes in comminuting devices: 1. Theory, Powder Technol. $107 \quad$ (2000) 93-107. https://doi.org/10.1016/S0032-5910(99)00175-8.

[46] F.J. Gotor, M. Achimovicova, C. Real, P. Balaz, Influence of the milling parameters on the mechanical work intensity in planetary mills, Powder Technol. 233 (2013) 1-7. https://doi.org/10.1016/j.powtec.2012.08.031.

[47] D.T. Morelli, T. Caillat, J. Fleurial, A. Borshchevsky, J. Vandersande, B. Chen, C. Uher, Lowtemperature transport properties of p-type $\mathrm{CoSb}_{3}$, Phys. Rev. B. Condens. Matter. 51 (1995) 9622-9628. https://doi.org/10.1103/physrevb.51.9622.

[48] C. Uher, Chapter 5 Skutterudites: Prospective novel thermoelectrics, in: T.M.B.T.-S. and S. Tritt (Ed.), Recent Trends Thermoelectr. Mater. Res. I, Elsevier, 2001: pp. 139-253. https://doi.org/10.1016/S0080-8784(01)80151-4.

[49] T. Caillat, A. Borshchevsky, J. -P. Fleurial, Properties of single crystalline semiconducting $\mathrm{CoSb}_{3}$, J. Appl. Phys. 80 (1996) 4442-4449. https://doi.org/10.1063/1.363405.

[50] J.W. Sharp, E.C. Jones, R.K. Williams, P.M. Martin, B.C. Sales, Thermoelectric properties of $\mathrm{CoSb}_{3}$ and related alloys, J. Appl. Phys. 78 (1995) 1013-1018. https://doi.org/10.1063/1.360402.

[51] M.S. Toprak, C. Stiewe, D. Platzek, S. Williams, L. Bertini, E. Müller, C. Gatti, Y. Zhang, M. Rowe, M. Muhammed, The Impact of Nanostructuring on the Thermal Conductivity of Thermoelectric $\mathrm{CoSb}_{3}$, Adv. Funct. Mater. 14 (2004) 1189-1196. https://doi.org/10.1002/adfm.200400109.

[52] Y. Kawaharada, K. Kurosaki, M. Uno, S. Yamanaka, Thermoelectric properties of $\mathrm{CoSb}_{3}, \mathrm{~J}$. Alloys Compd. 315 (2001) 193-197. https://doi.org/10.1016/S0925-8388(00)01275-5.

[53] O.L. Arnache, J. Pino, L.C. Sánchez, Determination of milling parameters useful on the 
formation of $\mathrm{CoSb}_{3}$ thermoelectric powders by low-energy mechanical alloying, J. Mater. Sci. Mater. Electron. 27 (2016) 4120-4130. https://doi.org/10.1007/s10854-016-4271-5.

[54] J. Yang, Y. Chen, J. Peng, X. Song, W. Zhu, J. Su, R. Chen, Synthesis of CoSb 3 skutterudite by mechanical alloying, J. Alloys Compd. $375 \quad$ (2004) 229-232. https://doi.org/10.1016/j.jallcom.2003.11.036.

[55] A. Perejón, N. Murafa, P.E. Sánchez-Jiménez, J.M. Criado, J. Subrt, M.J. Diánez, L.A. PérezMaqueda, Direct mechanosynthesis of pure $\mathrm{BiFeO}_{3}$ perovskite nanoparticles: reaction mechanism, J. Mater. Chem. C. 1 (2013) 3551-3562. https://doi.org/10.1039/C3TC30446A.

[56] F. Fischer, N. Fendel, S. Greiser, K. Rademann, F. Emmerling, Impact Is Important—Systematic Investigation of the Influence of Milling Balls in Mechanochemical Reactions, Org. Process Res. Dev. 21 (2017) 655-659. https://doi.org/10.1021/acs.oprd.6b00435.

[57] H. Kulla, M. Wilke, F. Fischer, M. Röllig, C. Maierhofer, F. Emmerling, Warming up for mechanosynthesis - temperature development in ball mills during synthesis, Chem. Commun. 53 (2017) 1664-1667. https://doi.org/10.1039/C6CC08950J.

[58] E. Napolitano, G. Mulas, S. Enzo, F. Delogu, Kinetics of mechanically induced anatase-to-rutile phase transformations under inelastic impact conditions, Acta Mater. 58 (2010) 3798-3804. https://doi.org/10.1016/j.actamat.2010.03.024.

[59] L. Takacs, Self-sustaining reactions induced by ball milling, Prog. Mater. Sci. 47 (2002) 355414. https://doi.org/10.1016/S0079-6425(01)00002-0.

[60] A.M. Belenguer, A.A.L. Michalchuk, G.I. Lampronti, J.K.M. Sanders, Understanding the unexpected effect of frequency on the kinetics of a covalent reaction under ball-milling conditions, Beilstein J. Org. Chem. $15 \quad$ (2019) 1226-1235. https://doi.org/https://doi.org/10.3762/bjoc.15.120.

[61] F.K. Urakaev, V. V Boldyrev, Mechanism and kinetics of mechanochemical processes in comminuting devices: 2. Applications of the theory. Experiment, Powder Technol. 107 (2000) 197-206. https://doi.org/10.1016/S0032-5910(99)00200-4.

[62] M. Hegedüs, M. Baláž, M. Tešinský, M.J. Sayagués, P. Siffalovic, M. Krul'aková, M. Kaňuchová, J. Briančin, M. Fabián, P. Baláž, Scalable synthesis of potential solar cell absorber $\mathrm{Cu}_{2} \mathrm{SnS}_{3}$ (CTS) from nanoprecursors, J. Alloys Compd. 768 (2018) 1006-1015. https://doi.org/10.1016/j.jallcom.2018.07.284.

[63] P.Y. Butyagin, Kinetics and Nature of Mechanochemical Reactions, Russ. Chem. Rev. 40 (1971) 901-915. https://doi.org/10.1070/rc1971v040n11 abeh001982.

[64] S. Vyazovkin, N. Sbirrazzuoli, Isoconversional Kinetic Analysis of Thermally Stimulated Processes in Polymers, Macromol. Rapid Commun. 27 (2006) 1515-1532. https://doi.org/10.1002/marc.200600404.

[65] S. Vyazovkin, A.K. Burnham, J.M. Criado, L.A. Pérez-maqueda, C. Popescu, N. Sbirrazzuoli, Thermochimica Acta ICTAC Kinetics Committee recommendations for performing kinetic computations on thermal analysis data, Thermochim. Acta. 520 (2011) 1-19. https://doi.org/10.1016/j.tca.2011.03.034.

[66] P.A. Julien, I. Malvestiti, T. Friščić, The effect of milling frequency on a mechanochemical organic reaction monitored by in situ Raman spectroscopy, Beilstein J. Org. Chem. 13 (2017) 2160-2168. 10.3762/bjoc.13.216.

[67] V.A. Mamedov, Recent advances in the synthesis of benzimidazol(on)es via rearrangements of quinoxalin(on)es, RSC Adv. 6 (2016) 42132-42172. https://doi.org/10.1039/C6RA03907C.

[68] P. Budrugeac, J.M. Criado, F.J. Gotor, C. Popescu, E. Segal, Kinetic Analysis of Dissociation of Smithsonite from a Set of Non-isothermal Data Obtained at Different Heating Rates, J. Therm. Anal. Calorim. 63 (2001) 777-786. https://doi.org/10.1023/A:1010148306206. 


\section{Figures}

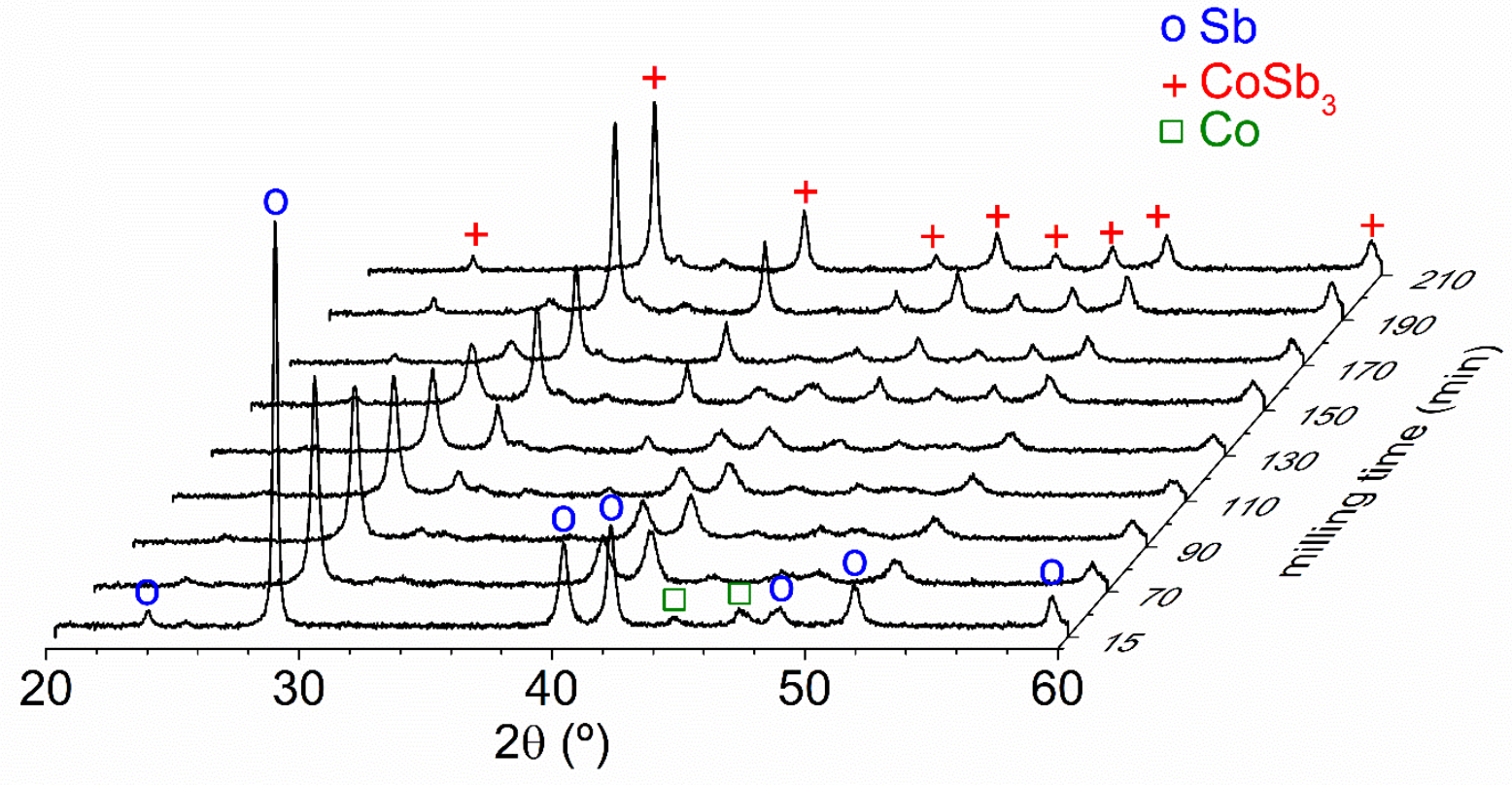

Figure 1. XRD patterns as a function of milling time under experimental condition 4 (Table 1)
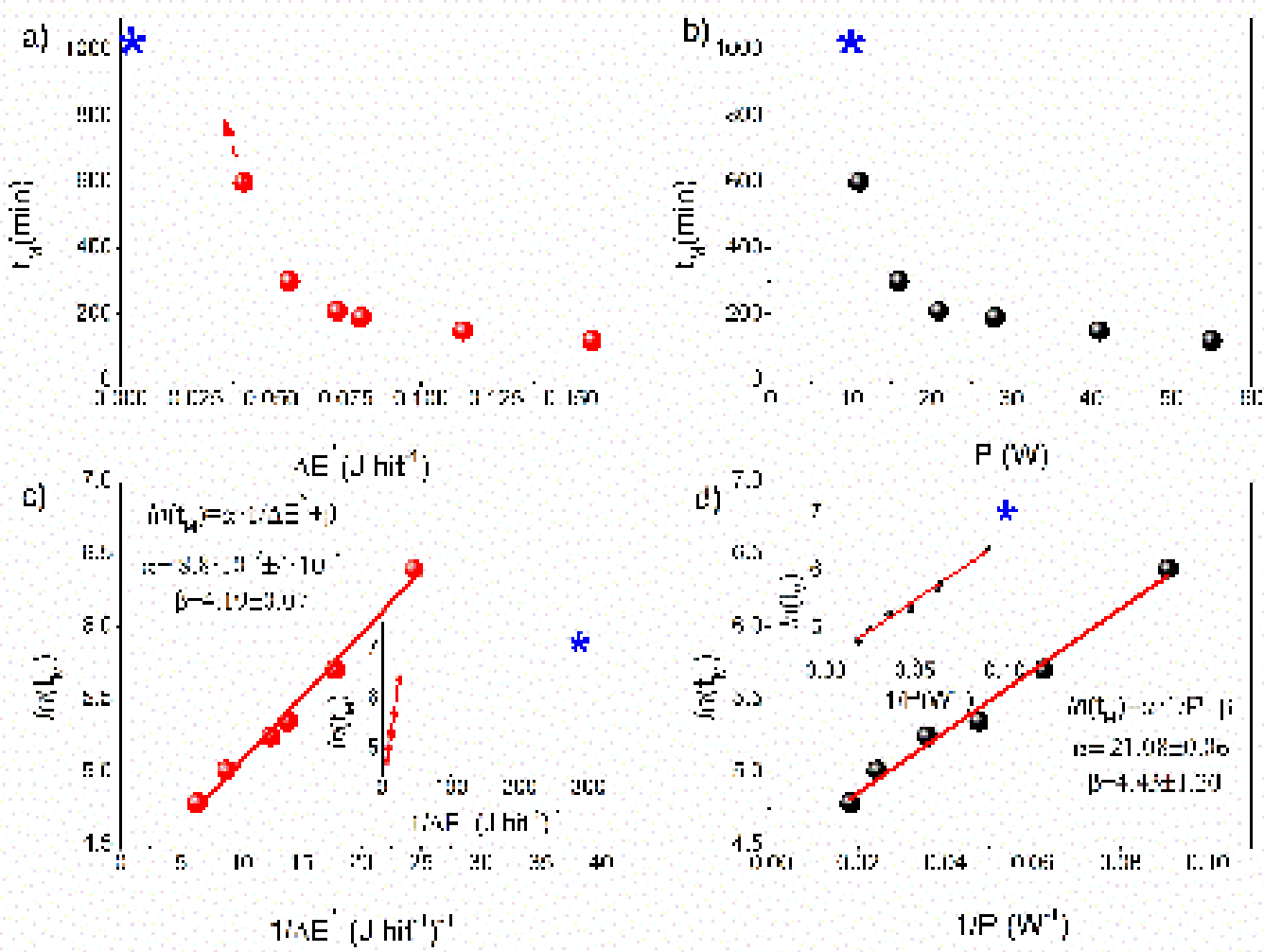
Figure 2. Evolution of the milling time required for the total consumption of raw materials with a) the corrected impact energy and b) the milling power. Natural logarithm of time against the reverse of c) the impact energy and d) the milling power along with the obtained linear fit. The blue star in figures a) and $b$ ) and the inset of figures c) and d) represents the data point for condition 1 (Table 1).

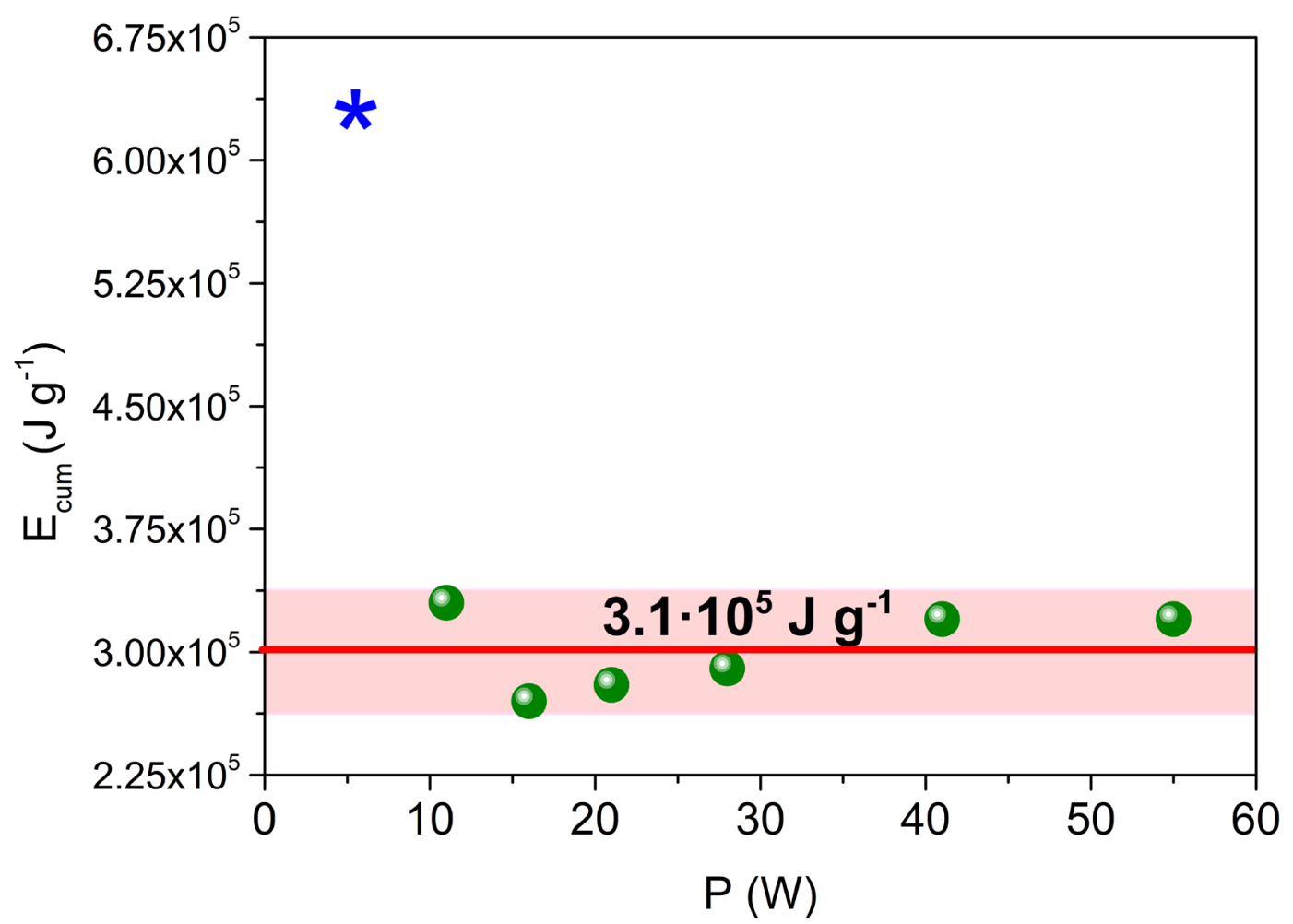

Figure 3. Evolution of the total energy transferred per unit weight of powders, $E_{\text {cum, }}$, for the total transformation of the raw materials versus the input milling power applied under each experimental conditions (Table 1). The blue star represents the data point obtained for experimental condition 1 (Table $1)$. 


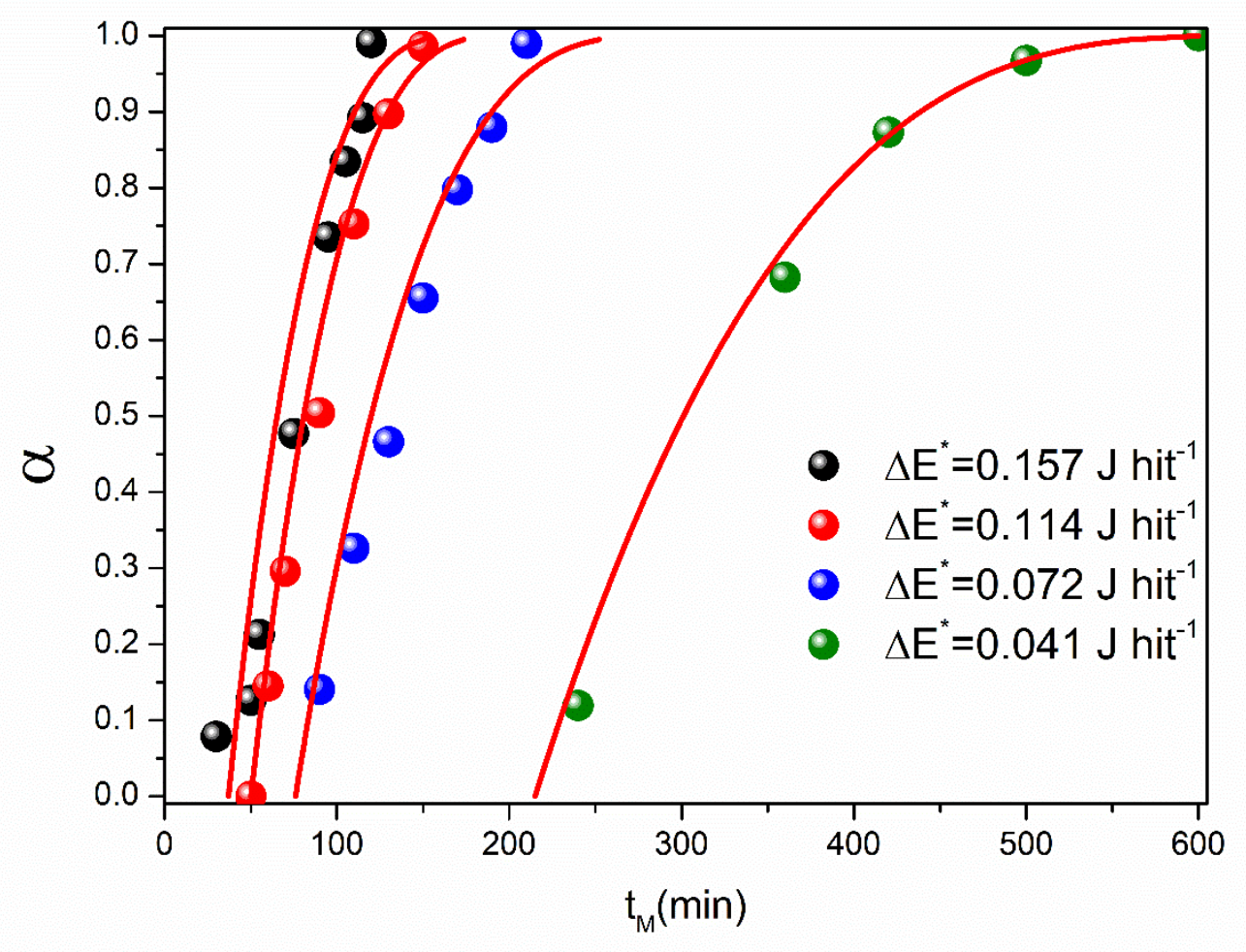

Figure 4. Experimental $\alpha$ - milling time curves (dots) corresponding to the conversion of starting materials (Co and $\mathrm{Sb}$ ) into $\mathrm{CoSb}_{3}$ at different impact energy 0.157, 0.114, 0.072 and $0.041 \mathrm{~J} \mathrm{hit}^{-1}$ (milling conditions 7, 6, 4 and 2, respectively). The simulated curves using the kinetic parameters obtained from the analysis are plotted as solid red lines. 
a)
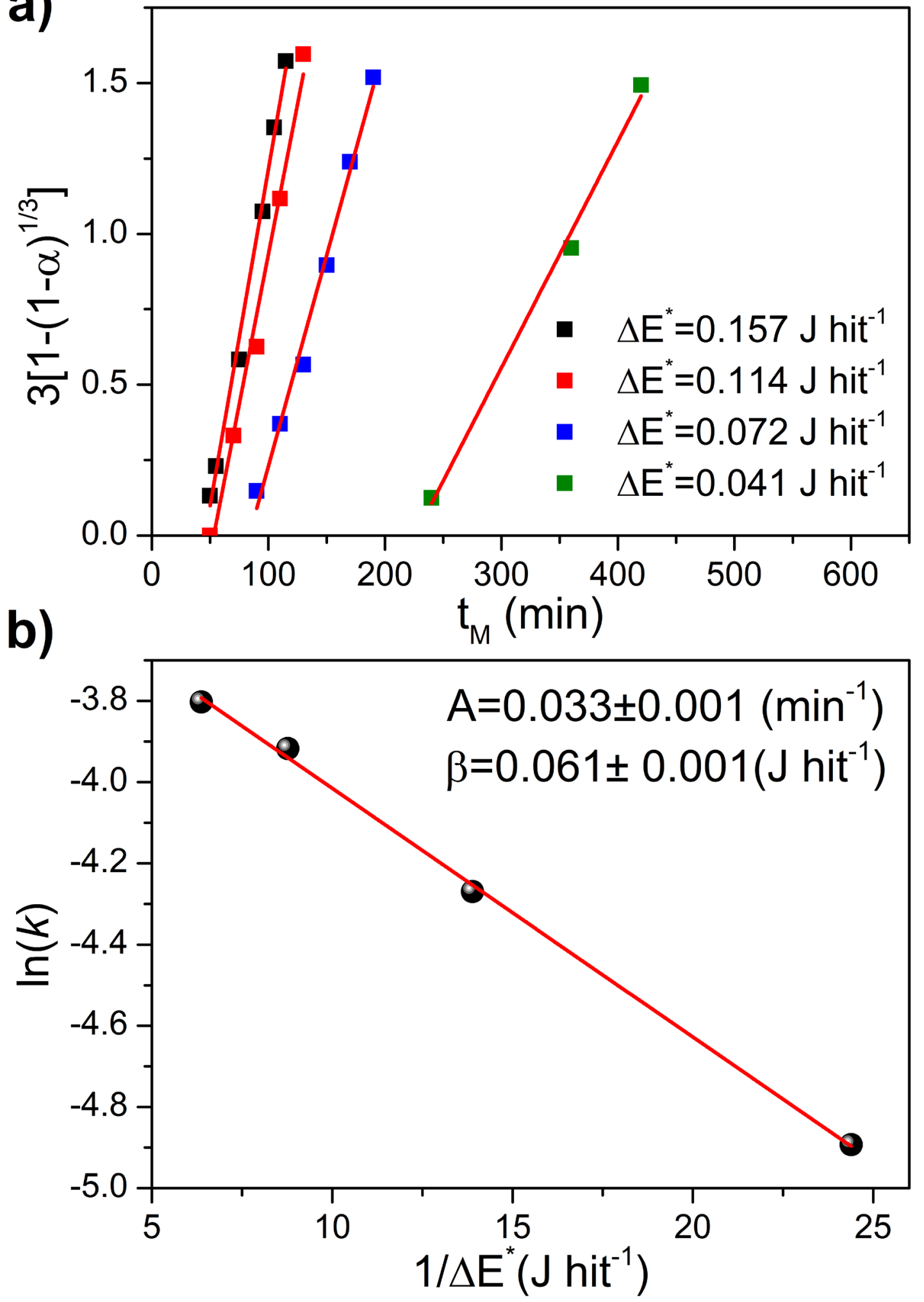

Figure 5. a) $g(\alpha)$ versus milling time for the $\alpha$-time curves presented in Figure 4, considering a R3 kinetic model. The linear fits obtained for the selected milling conditions performed under constant $\Delta E^{*}$ are also included. b) Logarithm of $\mathrm{k}$ against the reverse of $\Delta E^{*}$. 


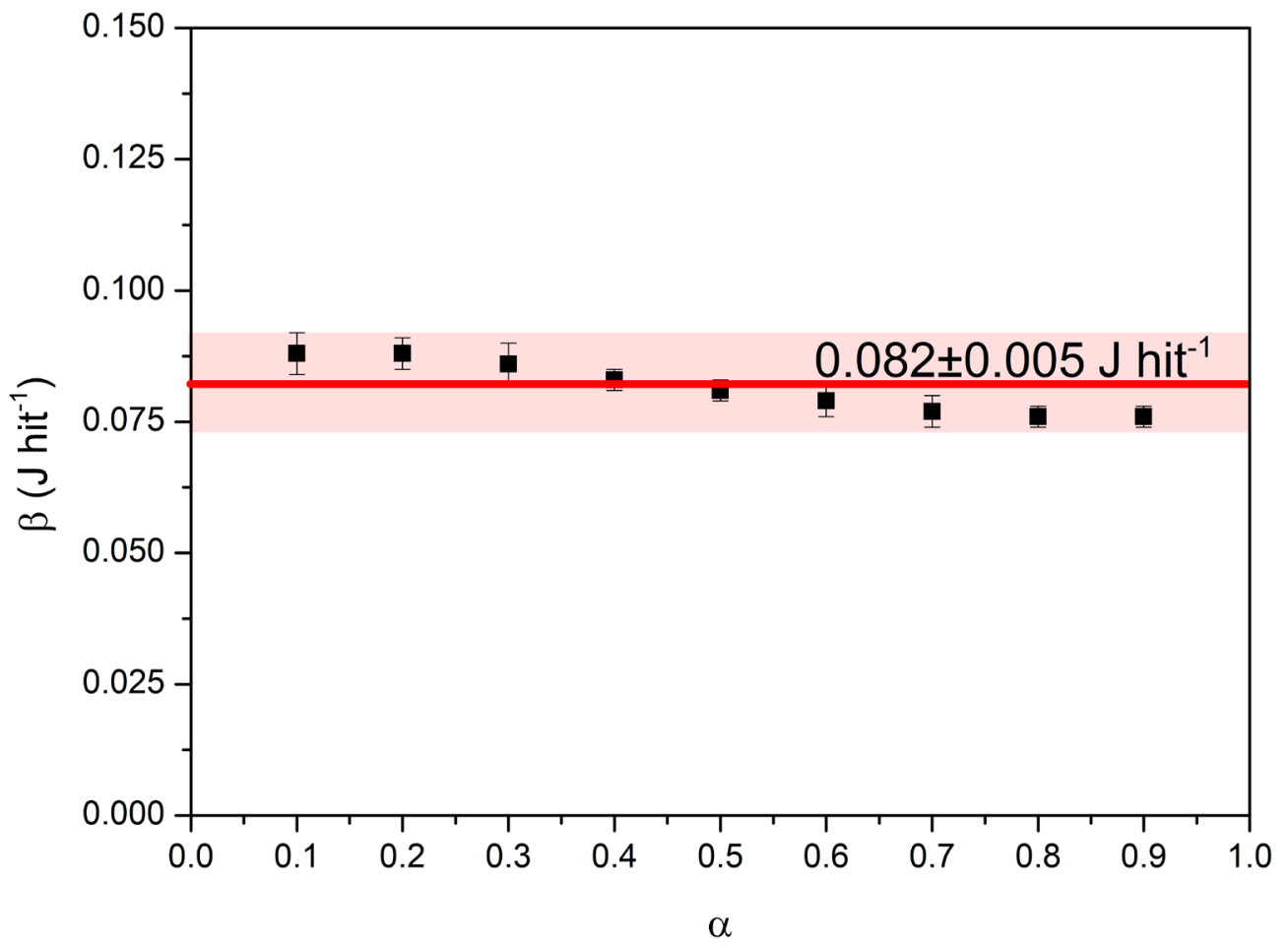

Figure 6. $\beta$ values as a function of $\alpha$, obtained from the isoconversional analysis of the experimental curves shown in Figure 4.

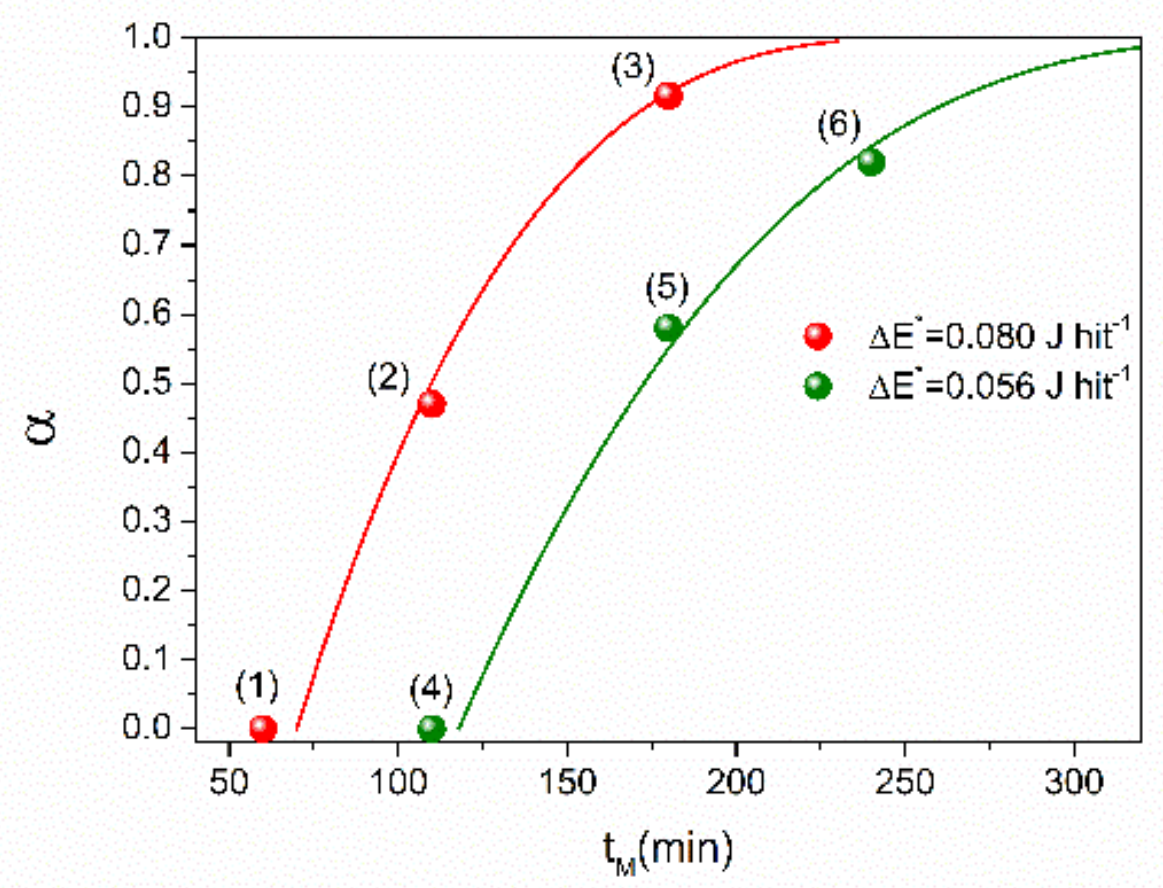

Figure 7. The predicted $\alpha$ - milling time curves (solid lines) using the kinetic parameters obtained from the analysis for milling conditions 3 and 5 (Table 1), which were not included in the kinetic analysis and correspond to an impact energy of 0.056 and $0.080 \mathrm{~J} \mathrm{hit}^{-1}$, respectively. The dots are experimental $\alpha$ - 
milling time data, which XRD patterns can be found in the supporting information (Figures $\mathrm{S} 7$ and $\mathrm{S}$ 8).

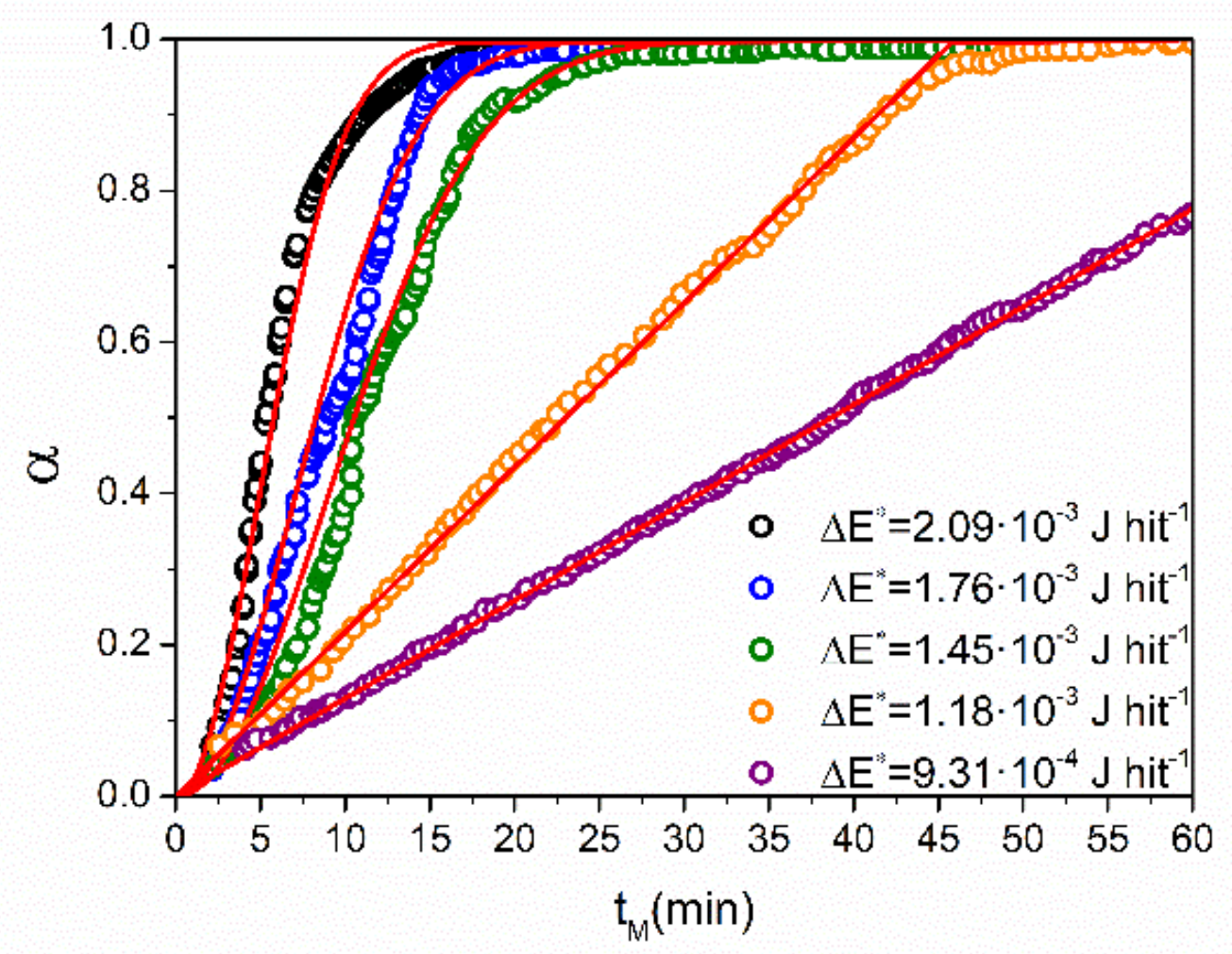

Figure 8. Experimental $\alpha$-milling time curves (dots) from ref. [66] corresponding to the formation of 2,3-diphenylquinoxaline. The simulated curves using the kinetic model and parameters contained in Table 4 are plotted as solid red lines. 